\title{
POSITIVISMO E MATEMÁTICA ESCOLAR DOS LIVROS DIDÁTICOS NO ADVENTO DA REPÚBLICA
}

\author{
WAGNER RODRIGUES VALENTE \\ Doutor pela Faculdade de Educação da USP \\ Professor da Pontifícia Universidade Católica de Santos - SP
}

RESUMO

\begin{abstract}
O estudo da presença da matriz positivista na história da educação brasileira vem sendo feito, muitas vezes, de forma mecânica e reducionista pela historiografia tradicional. A partir da perspectiva da história cultural, este artigo toma o livro didático como objeto cultural para mostrar que tipo de apropriação o cotidiano escolar realizou, por ocasião do advento da República, do pensamento positivista no ensino da matemática escolar. Tal análise concentra-se na resposta à questão: existiu, em algum momento da história da educação brasileira, uma matemática escolar positivista?
\end{abstract}

MATEMÁTICA-LIRRODIDÁTICO-ENSINODEMATEMÁTICA

\section{ABSTRACT}

POSITIVISM AND SCHOOL MATHEMATICS IN TEACHING TEXTBOOKS AT THE ADVENT OF THE REPUBLIC. The traditional historiography has been focusing the positivist influences in Brazilian's history of education in a very reducing way. Analysing the school mathematics textbooks as cultural objects this article will explain how the positivist thinking really contributed to mathematics' teaching in the period comprehending the end of Monarchy and the early Republic. 
estudo da presença da matriz positivista na história da educação brasileira vem sendo feito, muitas vezes, de forma mecânica e reducionista pela historiografia tradicional. A partir da perspectiva da história cultural, este artigo toma o livro didático como objeto para mostrar que tipo de apropriação o cotidiano escolar realizou, do pensamento positivista, no ensino da matemática escolar no Brasil.

A análise a ser empreendida remete à seguinte questão central: por ocasião do advento da República, marco histórico da influência positivista nos rumos da educação nacional, houve transformação na matemática escolar a ponto de podermos afirmar que tenha existido, em algum momento da história da educação brasileira, uma matemática escolar positivista?

\section{COMTE E A MATEMÁTICA}

Comte, como se sabe, elaborou uma hierarquia dos conhecimentos para o estudo da filosofia positiva: Matemática, Astronomia, Física, Química, Fisiologia e Física social. Dizia ele que tais conhecimentos representavam "a fórmula enciclopédica que, dentre o grande número de classificações que comportam as seis ciências fundamentais, é a única logicamente conforme à hierarquia natural e invariável dos fenômenos".

Em relação à Matemática, Comte afirmava que ela representava "o instrumento mais poderoso que o espírito humano pode empregar na investigação das leis dos fenômenos naturais". Afirmava, ainda, que era preciso considerá-la constituída por duas grandes ciências: "a matemática abstrata ou o cálculo, tomando a palavra em sua grande extensão, e a matemática concreta, que se compõe, duma parte, da geometria geral, de outra, da mecânica racional". Sobre a Geometria, Comte salientava que, como a mecânica, ambas deveriam "ser tomadas como verdadeiras ciências naturais, fundadas, assim como todas as outras, na observação, embora, por causa da extrema simplicidade de seus fenômenos, comportem um grau infinitamente mais perfeito de sistematização". Isso poderia, segundo ele, levar a desconhecer o caráter experimental de seus primeiros princípios.

Sinteticamente Comte conclui que:

.... ciência matemática deve, pois, constituir o verdadeiro ponto de partida de toda educação científica racional, seja geral, seja especial, o que explica o uso universal, que se estabeleceu desde há muito a esse propósito, duma maneira empírica, embora não tenha primitivamente outra causa que sua maior ancianidade relativa. (Comte, 1973a, p.44-5)

Em I85I, Augusto Comte fez publicar uma relação de 150 obras "a fim de dirigir os bons espíritos populares na escolha de seus livros habituais" (Comte, 1973, p. I I6). É uma relação dividida em quatro partes: Poesia, Ciência, História, Síntese. Dentro da divisão Ciência, encontramos no topo da lista a recomendação de que para o aprendizado da matemática elementar era preciso utilizar-se da Aritmética de Condorcet, da Álgebra e da Geometria de Clairaut, e mais a Trigonometria de Lacroix ou Legendre. 


\section{A REFORMA BENJAMIN CONSTANT}

Pelo Decreto n. 98 I de 8 de novembro de 1890, entra o Brasil na era republicana da educação. $\bigcirc$ ensino secundário, pensado conforme o colégio modelo da capital, o Ginásio Nacional (Colégio de Pedro II), teve alterado seu programa de estudos. Procurando seguir a orientação comtiana, Benjamin Constant torna-o enciclopédico e inclui todas as ciências da hierarquia positiva. São eliminadas disciplinas como Filosofia, Retórica e surgem outras como Astronomia, Sociologia Moral. Às matemáticas fica reservada grande parte do currículo:

$1^{\circ}$ ano: Aritmética e Álgebra elementar

$2^{\circ}$ ano: Geometria preliminar, Trigonometria retilínea e Geometria espacial, Desenho

$3^{\circ}$ ano: Geometria geral, seu complemento algébrico, Cálculo diferencial e integral, Geometria descritiva, Desenho

$4^{\circ}, 5^{\circ}, 6^{\circ}$ e $7^{\circ}$ anos: Revisão de cálculo e Geometria

No dizer de Fernando Azevedo:

Não houve, (...) uma instituição que não tivesse sido colhida pelas reformas do $1^{\circ}$ Ministro de Instrução da República; e, se quase todas elas acusam em maior ou menor grau a influência das idéias positivistas, foi na reorganização do Colégio Pedro II - ou Ginásio Nacional, segundo a denominação com que o batizou o novo regime -, e da Escola Normal do Distrito Federal, em que deixaram vinco mais profundo algumas das idéias do filósofo francês. (1976, p. I 23)

\section{DIDÁTICOS DE MATEMÁTICA INDICADOS POR COMTE}

A orientação comtiana sobre os livros de matemáticas elementares, que deveriam ser utilizados para a educação positivista, provoca a tradução para o português, em 1892 , da Geometria de Clairaut. O livro tem a dedicatória: "À memória de Benjamin Constant o Patriarca da República Brasileira”. No Posfácio do livro, assim se expressa o tradutor José Feliciano:

Inaugurando com este monumento de clareza a série de tentativas para trasladar a vernáculo as obras matemáticas da Biblioteca Positivista, tive sobretudo em mira aprender e facilitar a meus naturais o estudo da base lógica, imprescindível à iniciação enciclopédica. No dizer de Augusto Comte, é o melhor tratado didático sobre a geometria preliminar e pode ser compreendido sem outro auxílio. (Clairaut, 1892, p. 197)

Ainda no Posfácio, o tradutor menciona a existência de outras obras elementares 
indicadas por Comte, já traduzidas: a Aritmética de Condorcet e as Trigonometrias de Lacroix e Legendre!.

Afora tais obras, outros didáticos serão escritos no país, por professores brasileiros, que procurariam seguir o comtismo. Exemplos disso são os didáticos de Francisco Cabrita (1890) e Aarão e Lucano Reis ( 1892 ).

\section{CONDORCET, CLAIRAUT, LACROIX E LEGENDRE}

Ao indicar a Aritmética de Condorcet, Comte possivelmente procurou homenagear a figura-chave da escolarização francesa por seu projeto enciclopedista de ensino². Além disso, como destaca Miguel Lemos, no Prefácio da edição francesa editada no Brasil em 1903, o livro tem o predicado de "ser ao mesmo tempo Elementos de Aritmética e também Elementos de Lógica”" Noutros termos, Condorcet elimina, de suas explicações sobre as operações fundamentais da Aritmética com números inteiros, elementos de memorização, fórmulas e tabuadas. Condorcet, em cada lição do livro, vai descrevendo logicamente como efetuar cada operação. Não há exercícios propostos. Somente exemplos numéricos no desenvolvimento da teoria. Afora isso, o livro contém orientação aos professores primários para o ensino dos rudimentos da Aritmética.

Com Lacroix e Legendre, nada há de especial, salvo o fato de serem autores consagrados desde a Revolução Francesa, utilizados em todos os liceus franceses e escolas militares ${ }^{4}$.

Dos autores de compêndios didáticos de Matemática elementar indicados por Comte, talvez, aquele que mereceu maior atenção foi Clairaut. Tivesse Clairaut escrito uma Trigonometria, seria ela a indicada por Comte. Clairaut encarna os ideais de Comte para o ensino das matemáticas elementares, sobretudo a sua Geometria. Os Elementos de Geometria de Clairaut ( 1892 ) foram escritos bem de acordo com o modo de Comte

I. A Aritmética de Condorcet se refere ao livro Método para aprender a contar com segurança e facilidade cuja tradução é assinada pelas iniciais G.S.M., Rio de Janeiro: Livraria Nicolau Alves, I 883. As trigonometrias de Lacroix e Legendre estão contidas nos livros de Geometria dos autores. A obra de Legendre foi publicada pela Impressão Régia em 1809, com as primeiras gravações de figuras feitas no Brasil (Camargo, 1993, p.21) e reeditada várias vezes para uso, sobretudo nas escolas militares. Lacroix é o autor do primeiro compêndio didático de Geometria indicado para ser utilizado no Colégio de Pedro II em I 837 (Dória, 1937, p. I8).

2. Condorcet apresenta, em 1792, à Assembléia Nacional, um plano do que entendia por ensino científico. Nele colocava a Matemática como elemento fundamental, dava autonomia completa à Física tornando-a experimental, introduzia Química e Ciências Naturais colocando acento em suas aplicações úteis (Belhoste, 1995, p.25).

3. A Biblioteca Municipal de Santos, em São Paulo, possui dois exemplares da Aritmética de Condorcet. Um editado em I 883 já mencionado anteriormente; outro, em francês, cópia fiel do original, editado no Brasil pelo Apostolado Positivista do Brasil - Biblioteca Positivista, Rio de Janeiro, em 1903: Moyens d'apprendre à compter surement et avec facilité. O livro é prefaciado por Miguel Lemos.

4. Entre nós os livros de Lacroix e Legendre foram utilizados desde a vinda da Família Real portuguesa para o Brasil. São autores indicados na Carta Régia que cria a Academia Real Militar em 1810. 
considerar a Geometria: "uma ciência natural fundada na observação". Clairaut, a partir da necessidade prática de medir terrenos, desenvolveu sua Geometria sem qualquer preocupação com rigor ou formalismo matemático. Para que tenhamos idéia do que isso quer dizer basta tomar como exemplo a definição dada por ele para reta perpendicular. "uma linha que cai sobre outra sem pender nem para um lado nem para outro, é perpendicular a essa linha". O próprio Clairaut, no Prefácio do livro, disse:

\begin{abstract}
Em alguns passos destes elementos, talvez me censurem por me reportar demasiado ao testemunho dos olhos, e por me não cingir bastante à exatidão rigorosa das demonstrações. Aos que tal censura me fizerem, peço observem que só trato pela rama as proposições cuja verdade se patenteia por pouco que nelas se atente. Assim faço sobretudo no começo, em que as mais das vezes se encontram proposições desse gênero, e isto por haver notado que desse modo aqueles que tinham propensão para a geometria, se compraziam em exercer seu espírito, ao passo que se desalentavam quando eram atochados de demonstrações, por assim dizer, inúteis. (p.XII)
\end{abstract}

\title{
MATEMÁTICA ESCOLAR ANTES E DEPOIS DO ADVENTO DA REPÚBLICA
}

Durante grande parte da segunda metade do século XIX, a Matemática escolar orientou-se pelas obras compiladas por Cristiano Benedito Ottoni ${ }^{5}$. Senador do Império e professor de matemática na Academia Real dos Guardas-Marinha, Ottoni compilou para Aritmética e Álgebra, os livros de Bourdon e, para Geometria, o livro de Vincent, autores franceses que escreveram didáticos para escolas militares ${ }^{6}$. Ottoni foi o primeiro autor de livros didáticos de aceitação e adoção nacional.

A substituição das obras de Ottoni, no Colégio Pedro II, referência para o ensino secundário do Império, inclui textos que, grosso modo, em nada modificam os conteúdos já estabelecidos em suas compilações relativas à Aritmética, Álgebra, Geometria e Trigonometria. A diferença dos textos didáticos que passaram a ser utilizados posteriormente aos de Ottoni está em sua forma didática. As obras de Ottoni seguem a estruturação

5. A trajetória de Ottoni pode ser conhecida pelo texto de Valente (1999).

6. Louis Pierre Marie Bourdon escreveu Eléments d'Algèbre em 1817 e tal livro didático foi reimpresso mais de 20 vezes até o fim do século XIX (Caplat, 1986). Bourdon escreveu ainda Eléments d'Arithmétique que, segundo o Catálogo da Bibliothèque Nationale de France - BNF, foi reimpresso 20 vezes entre 1824 e 1872. AlexandreJoseph-Hidulphe Vincent, de acordo com La Grande Encyclopédie (Paris: Société Anonyme, 1896, p. I.026) , foi matemático e erudito francês. Escritor de textos interessantes sobre a história das matemáticas gregas, Vincent era genro de Bourdon. Foi professor de matemática no Lycée Saint-Louis em Paris. Em 1826 escreve Cours de géométrie élémentaire, à l'usage des élèves qui se destinent à l'École Polytechnique ou aux Écoles militaires. Tal texto, pela análise que fizemos no Catálogo da BNF, sofreu várias modificações e, a partir de 1937, passou a ser redigido em conjunto com Bourdon. Finalmente em I844, a partir da 5 a edição, o livro teve em sua página de rosto os seguintes dizeres: Cours de Géométrie Élémentaire, par A.---H. Vincent, Professeur de mathématiques au Collège royal de Saint-Louis [...] Revu conjointement par l'auteur et par M. Bourdon - Inspecteur général des études, examinateur d'admission a l'École Polytechnique [...] Ouvrage adopté par l'Université. Esses são os autores e manuais escolares que servirão às compilações de Ottoni. 
clássica: apresentação teórica seguida de exemplo numérico. Não há exercícios para os alunos. Os textos que substituem Ottoni passam a ser escritos visando já ao uso pelos alunos. Incluem exercícios gradativos, exercícios com resposta final, exercícios sem resposta, resumos etc. Esse é o caso de textos de Aritmética e Álgebra do professor Adelino Serrasqueiro e da Geometria do professor Timótheo Pereira. O primeiro adotado, pelo Pedro II, desde 1891 até 1923, pela sua Álgebra, e o segundo, a partir de 1898 em substituição à Geometria de Ottoni.

Modificações houve muitas, dentro dos didáticos de Aritmética adotados no Pedro II. Foi na Aritmética que mais compêndios didáticos surgiram. Quase todos os livros, no entanto, representaram, como já dissemos, melhorias didáticas na apresentação dos textos para serem utilizados pelos alunos, sem qualquer modificação na estruturação dos conteúdos já clássicos: Na Aritmética, tais conteúdos estão dados por: Numeração, Operações com números inteiros, Frações, Complexos, Decimais, Divisibilidade, Potências e Raízes, Razões e Proporções, Progressões e Logaritmos.

\section{A ARITMÉTICA POSITIVISTA DE AARÃO E LUCANO REIS}

Curso Elementar de Matemática - teórico, prático e aplicado - organizado de acordo com os melhores autores pelo engenheiro civil Aarão Reis, ex-professor de matemática elementar na Escola Politécnica do Rio de Janeiro, e Lucano Reis, professor de matemática elementar e oficial da contadoria geral da guerra. ARITMÉTICA - cálculo de valores.

Esses são os dizeres da página de rosto da Aritmética "dos Reis" ( 1892$)$. Tal obra foi escrita em 1892. A estruturação do livro ${ }^{8}$ procura ser algo original, organizada a partir do fio condutor números. Assim, constituída em cinco partes, além da Introdução Geral, a Aritmética tem as seções: Números Inteiros, Números Fracionários, Números Incomensuráveis, Comparação dos Números (razão, proporção, progressões e logaritmos) e Aplicações (metrologia, regra de três).

Trata-se, no entanto, do ponto de vista do desenvolvimento do texto, de uma Aritmética como a de Ottoni. Os autores até mencionam a pretensão de substituir Ottoni quando afirmam, na Advertência da I a edição:

Organizando-o e publicando-o, acreditamos prestar algum serviço à mocidade estudiosa do nosso país, onde abundam um sem-número de compêndios estrangeiros - franceses principalmente - mas um único curso nacional de matemática elementar existe, o do Exmo. Sr. Senador

C.B. Ottoni, excelente para a época em que foi organizado e publicado, porém já um tanto

7. De acordo com os Programas de Ensino do Colégio Pedro II.

8. Tal livro pertence ao acervo da Feusp - Biblioteca "Paulo Bourroul". 
insuficiente para os estudos atuais, atento o desenvolvimento que, felizmente, vai sendo exigido no ensino desta matéria, no Brasil, até mesmo para os candidatos à matrícula nas Academias de Direito.

Tal justificativa estaria ligada, sobretudo, ao desenvolvimento dado ao tema Números Incomensuráveis não encontrado em Ottoni. Raja Gabaglia, que foi professor de matemática e depois diretor do Colégio de Pedro II, além de professor da Escola Naval, escreveu uma apreciação sobre o livro, que saiu publicada no Jornal do Comércio de 21 de maio de 1893, em que salienta, a propósito do tratamento dado aos Números Incomensuráveis, o seguinte:

A explanação das operações sobre incomensuráveis, da teoria dos radicais, dos erros, das operações abreviadas e dos números aproximados basta para dar ao livro dos Srs. Aarão e Lucano Reis, o lugar de honra entre os congêneres publicados em nossa língua ${ }^{9}$.

Tal diferencial, na Aritmética de Aarão e Lucano Reis, é, no entanto, algo que nada acrescentou do ponto de vista da Aritmética escolar. Os próprios programas do Pedro II da época em que o livro foi adotado ( 1898 ) excluíam do ensino da Aritmética, os conteúdos que envolviam Erros e Medidas.

A forma didática do texto "dos Reis" era a clássica: nada de proposição de exercícios. Teoria e exemplo numérico. Um texto didático que não estava dirigido aos alunos.

Aarão e Lucano Reis eram adeptos do positivismo e procuraram revestir seu texto de elementos comtistas. Estes incluem desde um capítulo especial dentro da Introdução Geral, denominado Idéias e definição de Lógica, até inúmeras citações de Comte ao longo do livro. Por exemplo, dentro do tema da "divisão", aparecia a seguinte citação:

A compreensão e respectiva assimilação da teoria da divisão é - no pensar autorizado do ilustre Condorcet (Moyens d'apprendre à compter surement et avec facilité) - um dos primeiros pontos em que o estudo da ciência determina seleção decisiva entre os diversos espíritos; conceito que o grande Augusto Comte reforça com o assentimento de sua incontestável autoridade suprema acrescentando ainda poder-se afirmar que quem se tiver saído bem de tal prova, é perfeitamente capaz de concluir com proveito a iniciação matemática e mesmo a de toda a série enciclopédica da ciência positiva (Synthèse subjective). (Reis, Reis, 1892, p.89)

Esses elementos foram objeto de crítica pelo mesmo Eugênio Raja Gabaglia, combativo antipositivista. Gabaglia expressou sua crítica ao livro, como já mencionamos antes, no Jornal do Comércio. Os comentários de Gabaglia, por também conterem elementos elogiosos ao livro, como se viu anteriormente, são colocados como Prefácio pelos

9. Raja Gabaglia incluirá, nos Elementos de Aritmética por [Frères de l'Instruction Chrétienne] F.l. C., dois capítulos ao final do livro com os temas Operações abreviadas e Erros relativos (Valente, 1999a). 
autores, a partir da segunda edição da obra. No artigo, ao criticar os elementos positivistas do livro, Gabaglia discorda dos autores inicialmente pela definição por eles dada de Matemática:

\footnotetext{
...logo no primeiro capítulo, a definição de Matemática é a dada por Comte, definição errônea e falha, porque, como observa Poinsot, o espírito na matemática não tem unicamente em vista a proporção ou a medida. Pode ainda considerar o número em si mesmo, a ordem e a situação das cousas sem nenhuma idéia das suas relações, nem das distâncias maiores ou menores que as separam! (Reis, Reis, 1892)
}

No entanto, essa querela é pouco significativa para a matemática escolar propriamente dita. Nem programas de ensino, nem pontos para exames preparatórios de época se importam com as discussões de âmbito filosófico sobre as matemáticas. Os pontos e conteúdos a ensinar já estavam dados desde Ottoni.

\section{A GEOMETRIA POSITIVISTA DE FRANCISCO CABRITA}

Francisco Carlos da Silva Cabrita foi professor da Escola Normal do Rio de Janeiro. Participou do Conselho Diretor da Instrução Primária e Secundária do Distrito Federal. Fez parte do grupo que analisou os programas de ensino antigos (do Império) com vistas à reformulação para os novos tempos de República. Ficou responsável pelas matemáticas.

Antes mesmo de sair a tradução dos Elementos de Geometria de Clairaut, Cabrita escreveu, em 1890, sua Geometria ${ }^{10}$. Escreveu-a acostada à obra de Clairaut. Ele próprio destaca, no Prefácio de seu didático:

Quem entregar-se ao trabalho de confrontar estes Elementos de Geometria com os publicados em 174 I por Clairaut, facilmente reconhecerá neles uma adaptação do plano traçado por esse "eminente precursor da regeneração do ensino matemático" às atuais exigências didáticas. (...) Na sua elaboração, ora traduzindo Clairaut, ora escrevendo por conta própria, afastei-me do alto rigor lógico a que deveria estritamente cingir-me se outro fosse o fim desta publicação.

Francisco Cabrita teve seu texto analisado brevemente pelo tradutor de Clairaut, José Feliciano, que deu o seguinte veredicto:

Depois de começado este trabalho veiu-nos às mãos um livro intitulado "Elementos de Geometria", em que o sr. F. Cabrita diz ter feito uma adaptação do plano traçado por Clairaut. Sua leitura, mesmo incompleta, mostra-nos que aí, a par da tradução literal de Clairaut, a par da supressão de muitos trechos insubstituíveis, se estadea certa preocupação de demonstrar teoremas, com algum matiz algébrico, que desnatura de todo em todo a rota gizada pelo "eminente precursor da regeneração do ensino matemático". (Clairaut, I892, p. 198)

10. O livro de F. Cabrita, em $3^{a}$ edição de 1896, pertence ao acervo da Biblioteca Municipal de São Paulo. 
Francisco Cabrita promoveu uma adaptação do texto de Clairaut. Procurou seguir a mesma estruturação, em quatro partes, da obra do autor francês:

- Dos meios que foram mais naturalmente empregados para se conseguir a medida dos terrenos;

- Do método geométrico de comparar as figuras retilíneas;

- Medidas das figuras circulares e suas propriedades;

- Da medida dos volumes e das superfícies dos corpos.

Com razão observa José Feliciano a preocupação algébrica e de demonstração de alguns teoremas por Cabrita em sua Geometria. Exemplos disso são as fórmulas de cálculo de volumes, de diagonais, fórmula de soma de ângulos internos de um polígono etc. Não diríamos que isso modificou completamente a obra de Clairaut. Mas há a indução do aluno ao uso de fórmulas e expressões acabadas para que sejam resolvidos os exercícios propostos por Cabrita ao final do livro. No entanto, o fato de colocar exercícios para os alunos resolverem e, em separado, listar as respostas, representou um avanço didático na construção do compêndio.

Ambos, o livro de Cabrita e a tradução de José Feliciano, expressam a preocupação de seguir a orientação de Comte em relação àquele que considera o manual mais apropriado para o ensino da Geometria elementar. É somente isso que explica a razão de, passados 150 anos, aparecerem adaptação e tradução de um compêndio escrito em |74| para uso nos anos 90 do século XIX no Brasil.

Clairaut foi manual escolar na França independentemente de ter sido ou não recomendado por Comte. A utilização de Clairaut está ligada, em França, à longa marcha de debates sobre o ensino da Geometria: intuitiva ou abstrata? Clairaut ou Euclides? Em I863, Victor Duruy, ministro francês, reforma o ensino orientando que o aprendizado de Geometria fosse feito não por Clairaut mas por Euclides. Dentre outras coisas, em sua exposição de motivos, ponderava que os alunos nada aprendiam com o ensino intuitivo, sem demonstrações e teoremas e isso era verificado nos resultados dos exames (Belhoste, 1995, p. 383-4).

Entre nós prevaleceu, como referência para o ensino de geometria, a abstrata, não a intuitiva. Essa referência é dada, sobretudo, pelos pontos para exames preparatórios aos cursos superiores.

\section{HOUVE UMA MATEMÁTICA ESCOLAR POSITIVISTA?}

A análise dos livros didáticos, como referência para o ensino de Matemática, mostrou-nos que a estruturação dessa disciplina teve uma autonomia relativa de sua organização devido às transformações políticas mais amplas ocorridas na vida brasileira. Senão vejamos: 
O ensino da Aritmética elementar em muito se serviu da Aritmética Elementar llustrada de Antonio Trajano "'. Um livro com uma infinidade de exercícios aos alunos, tabuadas e elementos pedagógicos muito diversos da estruturação orientada por Condorcet.

Considerar o ensino da geometria de modo intuitivo e prático, a exemplo de Clairaut, foi algo que não fez escola. A geometria escolar vinha seguindo seu curso desde Ottoni com um acento no rigor geométrico e assim continuou. Mesmo as geometrias compostas para o ensino primário, como a de Olavo Freire (Noções de Geometria Prática), em 1894 que teve cerca de 40 edições -, não seguiram o curso intuitivo (ver Freire, 1930). Intitulavamse práticas pois não continham demonstrações e sim muitos exercícios de aplicação de formulários e questões ligadas ao desenho geométrico ${ }^{12}$.

Mudanças curriculares, a partir da Reforma Benjamin Constant, como a introdução do cálculo infinitesimal, logo foram afastadas ${ }^{13}$.

Avaliações internas dos próprios positivistas brasileiros indicam o fracasso das intenções de mudança das práticas pedagógicas. Ao escrever a biografia de Benjamin Constant, Mendes faz as seguintes considerações sobre a reforma do ensino:

De que serve criarem-se cadeiras de sociologia e moral se estas cadeiras podem ser providas por qualquer cidadão que o governo entenda? Apela-se para concursos, mas quem vai julgar de tais concursos senão professores cujo prestígio inicial provêm do mesmo governo? Congregações metafísicas, sem dedicação social (...) como podem escolher dignos professores de sociologia e moral? Augusto Comte coordenou todas as ciências: pois bem, quantos professores seguem hoje no ensino da cosmologia e da biologia as indicações do nosso Mestre? Nem se quer Lógica (Matemática) é ensinada conforme ele a atribuiu. ( 892, p.428)

Os poucos livros didáticos brasileiros que expressavam adesão ao positivismo de Comte tiveram sua escrita e organização didática dadas desde Ottoni. Notas aqui e ali, citações de Comte e capítulos introdutórios que professavam o sistema comtiano não alteraram a matemática adotada para o ensino. Não passaram mais do que querelas entre os autores que em nada modificaram a prática pedagógica do ensino de matemática.

Dentro da própria produção acadêmica das matemáticas o papel do positivismo foi reduzido. Assim, apesar de Benjamin Constant e Antônio Carlos de Oliveira Guimarães terem sido professores de matemática, da Escola Central e do Colégio Pedro II, respecti-

I I. A Aritmética Elementar llustrada destinada ao ensino primário, com I a edição em 1879, teve sua 136 edição posta em circulação em 1958! (Bittencourt, 1993, p. 357).

12. Na carta, escrita por Menezes Vieira, utilizada como Prefácio do livro de Freire, há o seguinte comentário: "Sinto, entretanto, que tivesses em um ponto transigido com a rotina, preferindo problemas abstratos às questões práticas cuja resolução se oferece todos os dias na vida social." Vieira, a seguir, justifica o comentário aludindo a que Freire deveria guiar-se por Clairaut.

13. Roxo (1937, p.220) avalia do seguinte modo o fracasso da introdução de novos conteúdos, como o cálculo infinitesimal: "Tal estudo, todavia, sem nenhuma ligação com o resto do curso, onde não era desenvolvida a idéia de função, e feito de um ponto de vista excessivamente formalístico, tornou-se inútil e contraproducente." 
vamente, e sócios-fundadores, em 1876, da Sociedade Positivista do Rio de Janeiro, a marca positivista no desenvolvimento da matemática no Brasil não é nítida. Um levantamento de Dantes (1996, p.60) mostra-nos que no período de 1842 a I890, foram apresentadas um total de 25 teses e somente 8 dentre elas tiveram caráter positivista.

Assim, a análise de objetos culturais como o livro didático revela uma autonomia relativa da constituição da matemática escolar diante das transformações políticas ocorridas com a República. A marcha de constituição da disciplina matemática teve suas determinações mais diretamente ligadas aos padrões internacionais que às ingerências e turbulências da política brasileira. Ancorada na resistência de professores antipositivistas e na estruturação já clássica de manuais didáticos usados sobretudo na França ${ }^{14}$, a matemática escolar no Brasil parece ter permanecido imune às tentativas de sua reestruturação positivista, levando a concluir que não houve uma matemática escolar positivista, propriamente dita.

\section{REFERÊNCIAS BIBLIOGRÁFICAS}

AZEVEDO, F. A Transmissão da cultura. São Paulo: Melhoramentos, 1976.

BELHOSTE, B. Les Sciences dans l'enseignement secondaire français. Paris: INRP, 1995. (Textes Officiels)

BITTENCOURT, C.M.F. Livro Didático e conhecimento histórico: uma história do saber escolar, 1993. Tese (dout.) Departamento de História - USP.

CABRITA, F. C. S. Elementos de geometria. Rio de Janeiro, 1890.

CAMARGO, A.M.A. Bibliografia da Impressão Régia do Rio de Janeiro. São Paulo: Edusp; Kosmos, 1993.

CAPLAT, G. Les Inspecteurs généraux de l'instruction publique: dictionnaire biographique |802-19|4. Paris: INRP, Editions du CNRS, 1986.

CLAIRAUT, A. Elementos de geometria. São Paulo: Livraria Teixeira \& Irmão, 1892.

COMTE, A. Catecismo positivista. São Paulo: Abril Cultural, 1973b. (Os pensadores)

Curso de filosofia positiva. São Paulo: Abril Cultural, 1973a. (Os pensadores)

DANTES, M.A.M. Os Positivistas brasileiros e as ciências no final do século XIX: a ciência nas relações Brasil-França (1850-1950). São Paulo: Edusp, 1996.

14. Raja Gabaglia é exemplo fundamental a ser mencionado: reconhecido antipositivista, traduziu e trouxe para o Ginásio Nacional (Colégio Pedro II) a coleção de livros de matemática por F.I.C. (livros didáticos elaborados pelas congregações católicas da França). 
DÓRIA, E. Memória histórica comemorativa do $1{ }^{\circ}$ centenário do Colégio de Pedro II. Rio de Janeiro: Ministério da Educação, 1937.

FREIRE, O. Noções de geometria prática. 35. ed. Rio de Janeiro: Francisco Alves, 1930.

MENDES, R.T. Benjamin Constant: esboço de uma apreciação sintética da vida e da obra do fundador da República Brasileira. Rio de Janeiro: Igreja Positivista do Brasil, 1892.

REIS, A., REIS, L. Curso elementar de matemática: aritmética. Rio de Janeiro: Garnier, 1892.

ROXO, E. A Matemática na educação secundária. São Paulo: Nacional, 1937.

VALENTE, W.R. Há I 50 anos uma querela sobre a geometria elementar no Brasil: algumas cenas dos bastidores da produção do saber escolar. Bolema. Rio Claro, SP: Unesp, v. 12, n. 13, p. 44-61, 1999

Uma história da matemática escolar no Brasil: 1730- 1930. São Paulo: Annablume; Fapesp, 1999a. 